\title{
Aerosolized iloprost induces a mild but sustained inhibition of platelet aggregation
}

\author{
M. Beghetti*, G. Reber", P. de Moerloose ${ }^{\#}$, L. Vadas ${ }^{\star}$, A. Chiappe ${ }^{\Uparrow}$, I. Spahr-Schopfer ${ }^{+}$, \\ P.C. Rimensberger ${ }^{\S}$
}

Aerosolized iloprost induces a mild but sustained inhibition of platelet aggregation. M. Beghetti, G. Reber, P. de Moerloose, L. Vadas, A. Chiappe, I. Spahr-Schopfer, P.C. Rimensberger. C ERS Journals Ltd 2002.

ABSTRACT: Pathological studies have revealed that one of the main features encountered in the pulmonary vasculature of patients with pulmonary hypertension is the presence of thrombotic lesions. Open pilot studies have indicated that aerosolized iloprost may have beneficial effects in patients with pulmonary hypertension. The effects of aerosolized iloprost on platelet function and plasma cyclic adenosine monophosphate (cAMP) were studied.

Platelet aggregation and plasma cAMP were measured at baseline, $30 \mathrm{~min}, 4$ and $6 \mathrm{~h}$ after inhalation of $15 \mu \mathrm{g}$ iloprost in 10 healthy volunteers. Maximal platelet aggregation in response to adenosine diphosphate (ADP) $\left(2\right.$ and $\left.6 \mu \mathrm{mol} \cdot \mathrm{L}^{-1}\right)$, collagen $(2.5$ and $\left.5 \mu \mathrm{g} \cdot \mathrm{mL}^{-1}\right)$, epinephrine $\left(1.25\right.$ and $\left.5 \mu \mathrm{mol} \cdot \mathrm{L}^{-1}\right)$ and arachidonic acid $\left(0.5 \mathrm{mg} \cdot \mathrm{mL}^{-1}\right)$ was measured.

Platelet aggregation was significantly inhibited at $30 \mathrm{~min}$ in response to ADP (2 and $6 \mu \mathrm{mol} \cdot \mathrm{L}^{-1}$, epinephrine $\left(1.25\right.$ and $\left.5 \mu \mathrm{mol} \cdot \mathrm{L}^{-1}\right)$ and collagen $\left(2.5 \mu \mathrm{g} \cdot \mathrm{mL}^{-1}\right)$. It was still inhibited at $4 \mathrm{~h}$ in response to the same agents, but normalized at $6 \mathrm{~h}$. cAMP increased at $30 \mathrm{~min}$, from $27.3 \pm 1.2$ to $31.8 \pm 1.2 \mathrm{nmol} \cdot \mathrm{L}^{-1}$, remained increased at $4 \mathrm{~h}(29.2 \pm$ $\left.1.3 \mathrm{nmol} \cdot \mathrm{L}^{-1}\right)$ and normalized at $6 \mathrm{~h}\left(27.4 \pm 1.1 \mathrm{nmol} \cdot \mathrm{L}^{-1}\right)$.

Aerosolized iloprost induced a mild but sustained inhibition of platelet aggregation. Platelet aggregation inhibition may be one of the mechanisms which explains the beneficial effect of repeated inhalation of iloprost in pulmonary hypertension. Eur Respir J 2002; 19: 518-524.

\begin{abstract}
*Cardiology Unit, Hôpital des Enfants, Dept of Paediatrics, "\#ivision of Angiology and Haemostasis, Dept of Clinical Chemistry, University Hospital, ${ }^{+}$Anaesthesiology Unit, and ${ }^{\S} \mathrm{Neo}-$ natology and Intensive Care Division, Hôpital des Enfants, Dept of Paediatrics, Geneva, Switzerland.
\end{abstract}

Correspondence: M. Beghetti, Paediatric Cardiology Unit, Hôpital des Enfants, 1211 Genève 14, Switzerland. Fax: 41223824546

E-mail: maurice.beghetti@hcuge.ch

Keywords: Aerosols

cyclic AMP

iloprost

platelet aggregation

prostacyclin

Received: November 62000

Accepted after revision October 31 2001
Prostacyclin $\left(\mathrm{PGI}_{2}\right)$ is a naturally occurring prostaglandin described more than 20 yrs ago to be a potent antiaggregatory and vasodilatory agent [1]. $\mathrm{PGI}_{2}$ is primarily produced by the endothelial cells of the vascular intima and acts through specific receptormediated activation of membrane-bound adenylate cyclase, and a consequent increase in intracellular cyclic adenosine monophosphate (cAMP) [2].

Long-term continuous infusion of $\mathrm{PGI}_{2}$, also called epoprostenol, has been shown to improve physical capacity and reduce mortality in primary and secondary pulmonary hypertension [3-6]. The beneficial effect of this therapy may not be attributed to the sole vasodilator effect, as most of the patients do not respond acutely to an infusion of prostacyclin, but to its antiproliferative and antiaggregant effects [4]. FrIEDMAN et al. [7] showed that patients with primary pulmonary hypertension have platelet abnormalities, and that long-term infusion of $\mathrm{PGI}_{2}$ normalizes platelet function, which may explain in part its beneficial effect. A continuous infusion through a central line is required because of its short elimination half-life of 2-3 min. Inhalation of $\mathrm{PGI}_{2}$ has been shown to dilate pulmonary vessels selectively in experimental and clinical studies $[8,9]$. This route of administration would avoid the requirement of permanent venous access, the risks of systemic sideeffects and the hazards due to disruption of the infusion. However, its clinical effects last only 10-30 $\min [8,9]$.

The continuous infusion of an analogue of $\mathrm{PGI}_{2}$, iloprost, has shown the same efficacy in pulmonary hypertension [10]. Iloprost is pharmacologically similar to epoprostenol, with vasodilatory, vascular remodelling and platelet inhibitory properties, but is a more stable compound, with an elimination half-life of 20-30 min [11]. Daily repetitive inhalation of iloprost is a novel approach, which seems suitable for long-term therapy of pulmonary hypertension $[8,12,13]$. It may show advantages over inhaled $\mathrm{PGI}_{2}$ because of its prolonged, clinical effect of 60-120 min [8].

As for continuous $\mathrm{PGI}_{2}$ infusion, one of the possible mechanisms explaining the beneficial effect of inhaled iloprost may be related to its platelet inhibitory properties. The effect of inhaled iloprost on platelet function, however, has not yet been addressed. The aim of the current study was to assess the effects of iloprost inhalation on platelet function and plasma levels of cAMP in healthy human volunteers. 


\section{Methods}

\section{Subjects}

Institutional ethics committee approval and informed consent were obtained prior to recruiting 10 healthy adult volunteers (six males, four females), aged $26-53$ yrs (mean \pm SEM age; $40 \pm 2$ yrs), to participate in the study. None of the subjects had taken aspirin or other medication known to affect platelet function in the 3 weeks before the study.

\section{Design}

The study was conducted in the haemostasis laboratory to perform platelet function tests immediately after sampling. On arrival in the laboratory, subjects were asked to rest for $10 \mathrm{~min}$. They were sitting comfortably during inhalation. At baseline and $30 \mathrm{~min}, 4$ and $6 \mathrm{~h}$ following inhalation, blood sampling for platelet function tests and plasma cAMP measurements were performed. Transcutaneous oxygen saturation (Nellcor pulse oximeter N-180 finger probe; Nellcor N200 oxygen saturation monitor, Nellcor, Garbamed Libefeld, Switzerland) was monitored continuously during inhalation. Cuff blood pressure, on the opposite arm of blood sampling, was measured every 5 min during inhalation, and $30 \mathrm{~min}$, 4 and $6 \mathrm{~h}$ after inhalation. Heart and respiratory rate were also recorded following the same schedule.

\section{Administration of iloprost aerosol}

Iloprost (Ilomedin, Schering Schweiz AC, Schlieren, Switzerland) was prepared from a vial of $50 \mu \mathrm{g} \cdot 0.5 \mathrm{~mL}^{-1}$ diluted in $4.5 \mathrm{~mL}$ of $0.9 \% \mathrm{NaCl}$, to obtain a solution of $10 \mu \mathrm{g} \cdot \mathrm{mL}^{-1}$. A concentration of $15 \mu \mathrm{g}$ in a $3 \mathrm{~mL}$ volume was obtained from $1.5 \mathrm{~mL}$ of the solution and $1.5 \mathrm{~mL}$ of $\mathrm{NaCl} 0.9 \%$, and then placed in the nebulizing chamber. All aerosols were generated by a jet nebulizer Pari LL (PARI GmbH, Starnberg, Germany), allowing nebulization only during inspiration, driven by a PARI Master air compressor (PARI GmbH). This device produces particles with a mass median aerodynamic diameter of $2.8 \mu \mathrm{m}$ with $>80 \%$ of the particles measuring $<5 \mu \mathrm{m}$. The subjects were instructed to inhale through a mouthpiece at $5-10 \mathrm{breath} \cdot \mathrm{min}^{-1}$ with tidal volume respiration over $10 \mathrm{~min}$.

\section{Placebo-controlled group}

Following the same design, four out of the 10 volunteers (three male and one female, mean \pm SEM age; $43 \pm 5$ yrs) were used as controls too, by inhaling $3 \mathrm{~mL}$ normal saline $(\mathrm{NaCl} 0.9 \%)$ to obtain placebocontrolled data.

\section{Blood sampling}

Blood was collected from an antecubital vein using a vacutainer technique. The first $3 \mathrm{~mL}$ of blood were collected in an ethylenediamine tetra-acetic acid vacutainer (Becton Dickinson Vacutainer systems Europe, Meylan, France) and processed for cAMP measurements, haemoglobin and platelet count (Sysmex K1000, Toa, Japan). The following $15 \mathrm{~mL}$ were collected in tubes anticoagulated with sodium citrate 0.129 M (1 in 10) (Becton Dickinson Vacutainer systems Europe) for platelet function studies.

\section{Platelet function studies}

Platelet-rich plasma was obtained by low-speed centrifugation and brought to $300 \mathrm{~g} \cdot \mathrm{L}^{-1}$ with plateletpoor plasma. Aggregation was performed with a PAP4 aggregometer (Bio Data, Horsham, PA, USA). It allows a photometric recording of platelet aggregation, based upon changes in platelets dispersed in a plasma environment when challenged with different agonists. The agonists were: 1) 2 and $6 \mu \mathrm{mol} \cdot \mathrm{L}^{-1}$ adenosine diphosphate (ADP); 2) 1.25 and $5 \mu \mathrm{mol} \cdot \mathrm{L}^{-1}$ epinephrine; 3) $0.5 \mathrm{mg} \cdot \mathrm{mL}^{-1}$ arachidonic acid; and 4) 2.5 and $5 \mu \mathrm{g} \cdot \mathrm{mL}^{-1}$ collagen. The platelet aggregometer was tested first with platelet-poor plasma to set the $100 \%$ baseline, and with nonstimulated platelet-rich plasma to set the $0 \%$ baseline. Interpretation of aggregation and thus of platelet function was based on the maximal percentage of aggregation at $5 \mathrm{~min}$.

Platelet function was investigated also by measuring the closure time of epinephrine or ADP collagencoated membranes with the Platelet Function Analyser PFA100 (Dade Behring, Düdingen, Switzerland). The PFA-100 is an instrument and test cartridge system in which the process of platelet adhesion and aggregation following a vascular injury is simulated in vitro [14]. Reference normal ranges for the study laboratory are 71-118 s for ADP and 93-194 s for epinephrine.

\section{Cyclic adenosine monophosphate measurements}

Plasma was obtained by immediate centrifugation at $1,600 \times g$ for $10 \mathrm{~min}$ at $4^{\circ} \mathrm{C}$, and then stored at $-70^{\circ} \mathrm{C}$ until analysis. cAMP levels were determined in batches using a commercial solid phase radioimmunoassay kit (Immunotech, Biffilman laboratories AG, Basel, Switzerland). The assay has a measurement range of $5-50 \mathrm{nmol} \cdot \mathrm{L}^{-1}$ with a sensitivity of $0.2 \mathrm{nmol} \cdot \mathrm{L}^{-1}$.

\section{Statistical analysis}

Mean and median, 75th and 25th percentile, standard deviation (SD) and standard error of the mean (SEM) were calculated for all parameters. Results are expressed as mean \pm SEM unless otherwise indicated. For each parameter, analysis of variance (ANOVA) for normally distributed data or the Friedman's test for data not normally distributed, were used for repeated measurements, with post hoc corrections, as appropriate, for all pairwise multiple comparisons (Tukey's or Dunn multiple comparison test). A value 
Table 1. - Maximal aggregation (\%) and platelet function analyser (PFA) closure time in response to the different agonists before and after inhalation of iloprost

\begin{tabular}{|c|c|c|c|c|c|}
\hline & Baseline & $30 \mathrm{~min}$ & $4 \mathrm{~h}$ & $6 \mathrm{~h}$ & p-value $\#$ \\
\hline \multicolumn{6}{|c|}{ Maximal aggregation \% } \\
\hline ADP $2 \mu \mathrm{M}$ & $47.3 \pm 9.1$ & $20.2 \pm 8.9 *$ & $35.8 \pm 8.6^{*}$ & $41.6 \pm 9.2$ & 0.005 \\
\hline ADP $6 \mu \mathrm{M}$ & $73.2 \pm 4.2$ & $60.1 \pm 4.5^{*}$ & $61.6 \pm 6.2^{*}$ & $63.1 \pm 5.1$ & 0.01 \\
\hline EPI $1.25 \mu \mathrm{M}$ & $49.3 \pm 9.1$ & $33.9 \pm 9.3 *$ & $37.1 \pm 10.4^{*}$ & $41.5 \pm 8.9$ & 0.009 \\
\hline EPI $5 \mu \mathrm{M}$ & $75.8 \pm 3$ & $58.6 \pm 6.1 *$ & $55 \pm 7.3^{*}$ & $65.9 \pm 6.1$ & 0.01 \\
\hline Coll $2.5 \mu \mathrm{g} \cdot \mathrm{mL}^{-1}$ & $80 \pm 2.2$ & $70.3 \pm 3.7 *$ & $77.6 \pm 2.3$ & $76.3 \pm 3.5$ & 0.04 \\
\hline Coll $5 \mu \mathrm{g} \cdot \mathrm{mL}^{-1}$ & $79.5 \pm 2.2$ & $76.8 \pm 2.4$ & $72.8 \pm 4.6$ & $78.9 \pm 2.3$ & 0.22 \\
\hline AA $0.5 \mathrm{mg} \cdot \mathrm{mL}^{-1}$ & $76 \pm 3.3$ & $64.3 \pm 6.5$ & $61.9 \pm 7.2$ & $71.3 \pm 3.1$ & 0.05 \\
\hline \multicolumn{6}{|l|}{ PFA closure time s } \\
\hline EPI & $168.6 \pm 19$ & $188.3 \pm 21.3$ & $194.6 \pm 22.1$ & $192.7 \pm 23$ & 0.38 \\
\hline ADP & $79.8 \pm 6.3$ & $81.5 \pm 6$ & $89.3 \pm 3.5$ & $89.7 \pm 5.4$ & 0.08 \\
\hline
\end{tabular}

Data are presented as mean \pm SEM unless otherwise stated. ADP: adenosine diphosphate; EPI: epinephrine; Coll: collagen; AA: arachidonic acid. ${ }^{\#}$ : $p$-value as determined by analysis of variance; *: $p<0.05$.

Table 2. - Maximal aggregation (\%) and platelet function analyser (PFA) closure time in response to the different agonists before, and after inhalation of placebo

\begin{tabular}{|c|c|c|c|c|c|}
\hline & Baseline & $30 \mathrm{~min}$ & $4 \mathrm{~h}$ & $6 \mathrm{~h}$ & ANOVA \\
\hline \multicolumn{6}{|c|}{ Maximal aggregation $\%$} \\
\hline ADP $2 \mu \mathrm{M}$ & $46.2 \pm 12.4$ & $42.5 \pm 9.5$ & $39.3 \pm 12.5$ & $41.3 \pm 4.2$ & NS \\
\hline ADP $6 \mu \mathrm{M}$ & $69.1 \pm 6.9$ & $83.8 \pm 5.9$ & $71.6 \pm 8.7$ & $82.3 \pm 5.6$ & NS \\
\hline EPI $1.25 \mu \mathrm{M}$ & $43.3 \pm 6.2$ & $40.8 \pm 12.4$ & $48.2-10.9$ & $43.3 \pm 15.1$ & NS \\
\hline EPI $5 \mu \mathrm{M}$ & $53.1 \pm 11$ & $62.9 \pm 14.3$ & $52.1 \pm 13.3$ & $62.8 \pm 13.1$ & NS \\
\hline Coll $2.5 \mu \mathrm{g} \cdot \mathrm{mL}^{-1}$ & $84.3 \pm 8.6$ & $89.1 \pm 6.2$ & $84.6 \pm 6$ & $95 \pm 7$ & NS \\
\hline Coll $5 \mu \mathrm{g} \cdot \mathrm{mL}^{-1}$ & $70.4 \pm 5.2$ & $92.3 \pm 6.7$ & $81 \pm 43.7$ & $92.8 \pm 6.8$ & NS \\
\hline AA $0.5 \mathrm{mg} \cdot \mathrm{mL}^{-1}$ & $53.9 \pm 8.4$ & $66.1 \pm 4.2$ & $59.7 \pm 73.4$ & $85.1 \pm 9$ & NS \\
\hline \multicolumn{6}{|l|}{ PFA closure time s } \\
\hline EPI & $135.5 \pm 6$ & $154.8 \pm 20$ & $171.3 \pm 18$ & $157 \pm 25$ & NS \\
\hline ADP & $90 \pm 4$ & $81.5 \pm 7.1$ & $86.5 \pm 9.7$ & $92.5 \pm 3.3$ & NS \\
\hline
\end{tabular}

Data are presented as mean \pm SEM unless otherwise stated. ANOVA: analysis of variance; ADP: adenosine diphosphate; EPI: epinephrine; Coll: collagen; AA: arachidonic acid; NS: nonsignificant.

of $\mathrm{p}<0.05$ was considered to indicate statistical significance.

\section{Results}

\section{Platelet function studies}

Maximal aggregation in response to the different agonists and platelet function analyser (PFA) closure time before, during and after inhalation are presented in table 1. Platelet aggregation was significantly inhibited at $30 \mathrm{~min}$ in response to 2 and $6 \mu \mathrm{mol} \cdot \mathrm{L}^{-1} \mathrm{ADP}, 1.25$ and $5 \mu \mathrm{mol} \cdot \mathrm{L}^{-1}$ epinephrine and $2.5 \mu \mathrm{g} \cdot \mathrm{mL}^{-1}$ collagen. It was still inhibited at $4 \mathrm{~h}$ with the same agents, except collagen, and normalized at $6 \mathrm{~h}$. PFA closure times for ADP and epinephrine did not change significantly at any time (table 1). No changes in platelet aggregation or PFA closure times were observed in the placebo-controlled group (table 2).

\section{Plasma cyclic adenosine monophosphate concentrations}

The basal plasma cAMP level was 27.3 \pm $1.3 \mathrm{nmol} \cdot \mathrm{L}^{-1}$. cAMP increased $\left(31.8 \pm 1.2 \mathrm{nmol} \cdot \mathrm{L}^{-1}\right.$; $\mathrm{p}<0.001) 30 \mathrm{~min}$ after the beginning of iloprost inhalation, remained slightly elevated $4 \mathrm{~h}$ after inhalation $\left(29.2 \pm 1.3 \mathrm{nmol} \cdot \mathrm{L}^{-1} ; \mathrm{p}<0.05\right.$ versus baseline) and normalized completely at $6 \mathrm{~h}\left(27.4 \pm 1.1 \mathrm{nmol} \cdot \mathrm{L}^{-1}\right.$; nonsignificant versus baseline, but $\mathrm{p}<0.001$ versus 30 min) (fig. 1). Plasma cAMP levels did not change

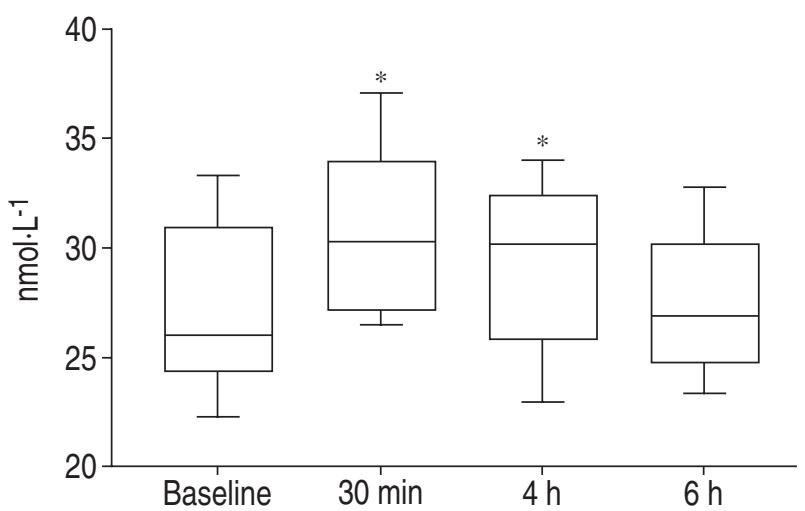

Fig. 1.- Plasma cyclic adenosine monophosphate levels before and after iloprost inhalation. The boxes show the concentration of the parameters. The boxes extend from the 25 th to the 75 th percentile, with a horizontal line representing the median value. Whiskers extend down to the minimal and up to the maximal values. *: $\mathrm{p}<0.05$ versus baseline. 
Table 3.-Blood pressure, heart rate and transcutaneous oxygen saturation before, during and after inhalation of iloprost

\begin{tabular}{|c|c|c|c|c|c|c|c|c|}
\hline & Baseline & $5 \mathrm{~min}$ & $10 \mathrm{~min}$ & $15 \mathrm{~min}$ & $30 \mathrm{~min}$ & $4 \mathrm{~h}$ & $6 \mathrm{~h}$ & p-value \\
\hline SBP mmHg & $116 \pm 3$ & $113 \pm 3$ & $110 \pm 3^{*}$ & $105 \pm 3^{*}$ & $106 \pm 3 *$ & $113 \pm 3$ & $114 \pm 3$ & $<0.0001$ \\
\hline DBP $\mathrm{mmHg}$ & $77 \pm 3$ & $73 \pm 2$ & $69 \pm 3 *$ & $65 \pm 4 *$ & $69 \pm 3 *$ & $74 \pm 3$ & $75 \pm 3$ & $<0.0001$ \\
\hline MBP mmHg & $90 \pm 2$ & $87 \pm 3$ & $81 \pm 3 *$ & $78 \pm 3 *$ & $79 \pm 3 *$ & $85 \pm 3$ & $85 \pm 2$ & $<0.0001$ \\
\hline $\mathrm{HR}$ beats $\cdot \mathrm{min}^{-1}$ & $76 \pm 3$ & $83 \pm 3 *$ & $85 \pm 3 *$ & $83 \pm 4 *$ & $77 \pm 4$ & $76 \pm 3$ & $75 \pm 3$ & $<0.0001$ \\
\hline Saturation $\%$ & $97.6 \pm 0.3$ & $99.5 \pm 0.2 *$ & $99.6 \pm 0.2 *$ & $98.8 \pm 0.3^{*}$ & $97.8 \pm 0.4^{*}$ & $97.5 \pm 0.3$ & $97.8 \pm 0.3$ & $<0.0001$ \\
\hline
\end{tabular}

Data are presented as mean \pm SEM. SBP: systolic blood pressure; DBP: diastolic blood pressure; MBP: mean blood pressure; HR: heart rate. ${ }^{\#}$ : repeated measures analysis of variance. ${ }^{*}: \mathrm{p}<0.05$ versus baseline.

in the placebo-controlled group $\left(22.7 \pm 2.5 \mathrm{nmol} \cdot \mathrm{L}^{-1}\right.$ at baseline, $21.1 \pm 1.4 \mathrm{nmol} \cdot \mathrm{L}^{-1}$ at $30 \mathrm{~min}, 21.9 \pm$ $1.9 \mathrm{nmol} \cdot \mathrm{L}^{-1}$ at $4 \mathrm{~h}$ and $22.1 \pm 1.2 \mathrm{nmol} \cdot \mathrm{L}^{-1}$ at $6 \mathrm{~h}$ ).

\section{Effects on blood pressure and transcutaneous oxygen saturation}

Changes in blood pressure, heart rate and transcutaneous oxygen saturation are described in tables 3 and 4. A small but significant decrease in systolic, diastolic and mean blood pressure was observed during iloprost inhalation. Blood pressure returned to baseline values at 4 and $6 \mathrm{~h}$ after inhalation. Cardiac frequency increased significantly during inhalation and returned to baseline immediately after. Transcutaneous oxygen saturation also showed an increase during inhalation.

Except for transient headaches and facial flush in two subjects, no adverse events were observed. There were no changes in any of the variables in the placebocontrolled group.

\section{Discussion}

These results show that aerosolized iloprost induces a mild but sustained inhibition of platelet aggregation in systemic venous blood. This effect seems to be mediated, as it occurs with endogenous $\mathrm{PGI}_{2}$, through an increase in cAMP.

Intravenous administration of iloprost in human volunteers [15] and patients with peripheral arterial occlusive disease [16] or angina pectoris [17] induces an inhibition of platelet aggregation in response to the same agonists as those used in the present study. The results shown here also indicate that it inhibits platelet aggregation when administered by inhalation. BURGHUBER et al. [18] showed that $\mathrm{PGI}_{2}$ administered by inhalation caused an inhibition of ADP-induced platelet aggregation. Although a short-acting substance $\mathrm{PGI}_{2}$ was used in their patients, and the effect was still present $30 \mathrm{~min}$ after the end of inhalation. With iloprost, inhibition of platelet aggregation seems even more prolonged due to its longer half-life. In this study, the effect on platelets is mild but prolonged as it is still present $4 \mathrm{~h}$ after inhalation. The clinical effects of iloprost administered by inhalation, based on the effect on pulmonary arterial pressure, is estimated at 60-120 min [8], but it has been shown that the platelet inhibition may last longer than vasodilation [19]. A continuous release of iloprost after deposition in the lungs may be an explanation of this long-lasting inhibition of platelet aggregation, but this question cannot be answered by the present study. Objective markers of systemic platelet effects disappear $6 \mathrm{~h}$ after iloprost inhalation. This needs to be remembered as most of the patients treated with inhaled iloprost in clinical studies do not inhale their drugs at night. This may lead to a lack of efficacy in the morning. This may be detrimental to the patient. Approaches leading to prolonged iloprost effects, such as the use of phosphodiesterase inhibitors, may be of value [20].

The inhibition of platelet aggregation induced by inhaled iloprost in this study has to be considered as a mild effect, as it is more pronounced with the lowest doses of ADP, epinephrine and collagen, and not present with arachidonic acid which is considered to be the most potent of these agonists. In addition, the indirect assessment of bleeding time, through the measurements of PFA closure time, shows that the potential risk of bleeding remains low. Similar results were obtained with $\mathrm{PGI}_{2}$ in a study by vAN HEERDEN et al. [21], where they found inhibition of platelet aggregation using platelet aggregometry in response to ADP and collagen, but the thromboelastogram remained normal. No episodes of bleeding have been reported so far with the use of inhaled $\mathrm{PGI}_{2}$ or iloprost. However, the use of this therapy in patients with a risk of bleeding, such as postcardiopulmonary

Table 4.-Blood pressure, heart rate and transcutaneous oxygen saturation before, during and after inhalation of placebo

\begin{tabular}{lrrrrrrrr}
\hline & Baseline & $5 \mathrm{~min}$ & $10 \mathrm{~min}$ & $15 \mathrm{~min}$ & $30 \mathrm{~min}$ & $4 \mathrm{~h}$ & $6 \mathrm{~h}$ & $\mathrm{p}$-value \\
\hline SBP mmHg & $109 \pm 5$ & $110 \pm 5$ & $108 \pm 4$ & $107 \pm 4$ & $111 \pm 7$ & $111 \pm 7$ & $114 \pm 8$ & NS \\
DBP mmHg & $70 \pm 5$ & $70 \pm 6$ & $72 \pm 7$ & $72 \pm 8$ & $68 \pm 8$ & $66 \pm 7$ & $70 \pm 7$ & NS \\
MBP mmHg & $77 \pm 6$ & $78 \pm 8$ & $80 \pm 7$ & $78 \pm 6$ & $76 \pm 6$ & $71 \pm 6$ & $75 \pm 4$ & NS \\
HR beats·min & $67 \pm 7$ & $66 \pm 6$ & $66 \pm 4$ & $64 \pm 5$ & $63 \pm 7$ & $70 \pm 8$ & $65 \pm 6$ & NS \\
Saturation \% & $97.3 \pm 0.9$ & $98.3 \pm 1$ & $98.8 \pm 1$ & $98.8 \pm 0.6$ & $97 \pm 0.4$ & $98 \pm 0.5$ & $98 \pm 0.3$ & NS \\
\hline
\end{tabular}

Data are presented as mean \pm SEM. SBP: systolic blood pressure; DBP: diastolic blood pressure; MBP: mean blood pressure; HR: heart rate; NS: nonsignificant. ${ }^{\#}$ : repeated measures analysis of variance. 
bypass patients with pulmonary hypertension [22], or particularly sensitive to the risk of bleeding, such as newborns or premature babies with pulmonary hypertension [23] may not be justified yet.

An increase in cAMP was associated with the inhibition of platelet aggregation. Most of the biological effects of iloprost are thought to be related to an intracellular increase of cAMP. In this study cAMP increased by $17 \%$; an early greater increase may have been missed as this level was measured 30 min after inhalation. However, plasma cAMP levels may not reflect the intraplatelets increase and this may explain the relatively low increase in cAMP. HARDY et al. [24] showed that, with $\mathrm{PGI}_{2}$, a peak in cAMP appears at $5 \mathrm{~min}$ and then stabilizes to a lower baseline at $10 \mathrm{~min}$ which remains increased for $45 \mathrm{~min}$. This long-lasting increase in cAMP, which is even more marked in the present study using inhaled iloprost, may explain the prolonged effect on platelet aggregation. Based on the results presented in this study, the inhibition of platelet aggregation associated with an increase in plasma cAMP levels, is believed to indicate a systemic absorption of iloprost during inhalation. This is confirmed by the slight decrease in blood pressure, especially the diastolic pressure, which may reflect a decrease in systemic vascular resistance. The appearance of facial flush and headaches in two subjects are characteristic signs observed with intravenous administration [25] and confirm a systemic spillover. In addition, similar effects were observed by HOEPER et al. [13] in patients treated with aerosolized iloprost.

There is evidence that intravascular coagulation in the pulmonary circulation may be a continuous process in pulmonary hypertension [26]. Moreover, platelet [7, 27] and plasma coagulation profile abnormalities [28] have been reported in patients with primary and secondary pulmonary hypertension, and the effect of oral anticoagulation has proven to be beneficial on survival [29]. Recently, studies analysing markers of platelet activation suggested that platelets of patients with pulmonary hypertension are not activated, but had an accelerated turnover and returned to normal after epoprostenol therapy [30]. An increase in the release of the vasoconstrictor, thromboxane $\mathrm{A}_{2}$ has been shown suggesting the activation of platelets occurs in both the primary and secondary forms of pulmonary hypertension [31]. In addition, the release of $\mathrm{PGI}_{2}$ is decreased in the same patients. TUDER et al. [32] showed that expression of $\mathrm{PGI}_{2}$ synthase was depressed in lungs from patients with pulmonary hypertension. Decreased $\mathrm{PGI}_{2}$ production might predispose patients to vasoconstriction and thrombosis in situ. This explains why aspirin, a well known antiplatelet drug is not used in pulmonary hypertension to prevent thrombosis. Aspirin has cyclooxygenase inhibitory effects that may aggravate pulmonary hypertension through the inhibition of endogenous prostaglandin production [33]. Continuous infusion of $\mathrm{PGI}_{2}$ results in clinical and haemodynamic improvement in patients with pulmonary hypertension and seems to be beneficial to endothelial function [34]. It has also been shown that continuous infusion of $\mathrm{PGI}_{2}$ decreases plasma levels of tissue plasminogen activator and plasminogen activator inhibitor-1 in primary pulmonary hypertension [35]. It has even been suggested that the activation of smooth muscle cell proliferation is the consequence of platelet aggregation on vessel walls [26]. Activation of platelets in pulmonary hypertension may not only induce local thrombosis but may contribute to vascular remodelling through the release of platelet-selective mediators such as thromboxane $A_{2}$, serotonin and growth factors [36]. All these findings prove that the platelet plays an important role in the pathophysiology of pulmonary hypertension. The antiplatelet effect observed in this study supports the use of inhaled iloprost and may explain in part the clinical improvement obtained with daily repetitive inhalations in patients with primary and secondary pulmonary hypertension.

This study shows some limitations. A dose-dependent effect has been demonstrated with intravenous administration of iloprost, but this was not evaluated in this study since only a single dose was given $[2,11$, $15,21]$. Dose-response curves would have been of benefit in order to compare the dose-dependent effect obtained with the intravenous admininistration. Higher doses of inhaled iloprost may have more pronounced systemic haemodynamic effects, such as hypotension, which would not be of benefit. However, $15 \mu \mathrm{g}$ does represent the mean dose used in clinical studies and therefore can be considered as representative. The exact dose delivered can only be estimated and is related to the nebulizer capacities. Although only little is known on particle size and lung distribution, the demonstration of changes in platelet aggregation, cAMP and systemic pressure provide proof of the effective drug delivery. Intraplatelet cAMP was not measured to confirm the activation of platelet adenylate cyclase, but based on in vitro experiments with iloprost, one can assume that this was the pathway leading to inhibition of platelet aggregation in this study [2].

The results show that the potentially beneficial effect on platelet function, obtained with continuous, intravenous prostacyclin infusion, may also be obtained with aerosolized iloprost. Considering the decreased prostacyclin and increased thromboxane $\mathrm{A}_{2}$ production, and the presence of microthrombi in peripheral lung vessels of patients with pulmonary hypertension, these results may explain in part the observed long-term effect of repetitive inhalation of iloprost in pulmonary hypertension. Further studies are required to confirm this effect in patients with pulmonary hypertension.

Acknowledgements. The authors would like to thank Schering AG, Zurich, Switzerland for providing iloprost.

\section{References}

1. Moncada S, Gryglewski R, Bunting S, Vane JR. An enzyme isolated from arteries transforms prostaglandin endoperoxides to an unstable substance that 
inhibits platelet aggregation. Nature 1976; 263: 663665.

2. Kerins MD, Murray R, Fitzgerald GA. Prostacyclin and prostaglandin E1: molecular mechanisms and therapeutic utility. Prog Hemost Thromb 1991; 10: 307-337.

3. Barst RJ, Rubin LJ, Long WA, et al. A comparison of continuous intravenous epoprostenol (prostacyclin) with conventional therapy for primary pulmonary hypertension. N Engl J Med 1996; 334: 296-301.

4. McLaughlin VV, Genthner DE, Panella MM, Rich S. Reduction in pulmonary vascular resistance with longterm epoprostenol (prostacyclin) therapy in primary pulmonary hypertension. N Engl J Med 1998; 338: 273-277.

5. Rosenzweig EB, Kerstein D, Barst RJ. Long-term prostacyclin for pulmonary hypertension with associated congenital heart defects. Circulation 1999; 99: $1858-1865$.

6. Higenbottam T, Wheeldon D, Wells F, Wallwork J. Long-term treatment of primary pulmonary hypertension with continuous intravenous epoprostenol (prostacyclin). Lancet 1984; 1: 1046-1047.

7. Friedman R, Mears JG, Barst RJ. Continuous infusion of prostacyclin normalizes plasma markers of endothelial cell injury and platelet aggregation in primary pulmonary hypertension. Circulation 1997; 96: 2782-2784.

8. Olschewski H, Walmrath D, Schermuly R, Chofrani A, Grimminger F, Seeger W. Aerosolized prostacyclin and Iloprost in severe pulmonary hypertension. Ann Intern Med 1996; 124: 820-824.

9. Walmrath D, Schneider T, Pilch J, Schermuly R, Grimminger F, Seeger W. Effects of aerosolized prostacyclin in severe pneumonia. Impact on fibrosis. Am J Respir Crit Care Med 1995; 151: 724-730.

10. Higenbottarn T, Butt AY, McMahon A, Westerbeck $\mathrm{R}$, Sharples L. Long term intravenous prostaglandin (epoprostenol or iloprost) for treatment of severe pulmonary hypertension. Heart 1998; 80: 151-155.

11. Grant SM, Goa KL. Iloprost: A review of its pharmacodynamic and pharmacokinetic properties and therapeutic potential in peripheral vascular disease, myocardial ischemia and extracorporeal circulation procedures. Drugs 1992; 43: 889-924.

12. Olschewski H, Chofrani HA, Walmrath D, Temmesfeld B, Grimminger F, Seeger W. Recovery from circulatory shock in severe puhnonary hypertension with aerosolization of iloprost. Intensive Care Med 1998; 24: 631-634.

13. Hoeper MM, Schwarze M, Ehlerding S, et al. Longterm treatment of primary pulmonary hypertension with aerozolized iloprost, a prostacyclin analogue. $N$ Engl J Med 2000; 342: 1866-1870.

14. Harrisson P, Robinson MSC, Mackie IJ, et al. Performance of the platelet function analyser PFA1000 in testing abnormalities of primary haemostasis. Blood Coagul Fibrinolysis 1999; 10: 25-31.

15. Krause W, Krais T. Pharmacokinetics and pharmacodynamics of the prostacyclin analogue iloprost in man. Eur J Clin Pharmacol 1986; 30: 61-68.

16. Darius H, Hossman V, Schrör K. Antiplatelet effects of intravenous iloprost in patients with peripheral arterial obliterative disease. Klin Wochenschr 1986; 64: 545-551.

17. Buggiardini R, Calvani M, Ferrini D, et al. Effects of iloprost, a stable prostacylin analogue, on exercise capacity and platelet aggregation in stable angina pectoris. Am J Cardiol 1986; 58: 453-459.

18. Burghuber OC, Silberbauer K, Haber P, Sinzinger H, Elliott M, Leithner C. Pulmonary and antiaggregatory effects of prostacyclin after inhalation and intravenous infusion. Respiration 1984; 45: 450-454.

19. van Heerden PV. Systemic levels of 6-ketoprostaglandin F1a following administration of inhaled aerosolized prostacyclin. Anaesth Intensive Care 1997; 25: 701-703.

20. Schermuly RT, Cofrani HA, Enke B, et al. Low-dose systemic phosphodiesterase inhibitors amplify the pulmonary vasodilator response to inhaled prostacyclin in experimental pulmonary hypertension. $\mathrm{Am}$ J Respir Crit Care Med 1999; 160: 1500-1506.

21. van Heerden PV, Gibbs NM, Michalopoulos N. Effect of low concentrations of prostacyclin on platelet function in vitro. Anaesth Intensive Care 1997; 25: 343-346.

22. Zwissler B, Rank N, Jaenicke U, et al. Selective pulmonary vasodilation by inhaled prostacyclin in a newborn with congenital heart disease and cardiopulmonary bypass. Anesthesiology 1995; 82: 1512 1516.

23. De Jaegere APMC, Anker JNVD. Endotracheal instillation of prostacyclin in preterm infants with persistent pulmonary hypertension. Eur Respir J 1998; 12: 932-934.

24. Hardy C, Robinson C, Lewis RA, Tatersfield E, Holgate ST. Airway and cardiovascular responses to inhaled prostacyclin in normal and asthmatic subjects. Am Rev Respir Dis 1985; 131: 18-21.

25. Scheeren $\mathrm{T}$, Radermacher P. Prostacyclin $\left(\mathrm{PGI}_{2}\right)$ : new aspects of an old substance in the treatment of critically ill patients. Intensive Care Med 1997; 23: 146-158.

26. Chaouat A, Weitzenblum E, Higenbottam T. The role of thrombosis in severe pulmonary hypertension. Eur Respir J 1996; 9: 356-363.

27. Nakonechnicov S, Gabbasov Z, Chazova I, Popov E, Belenkov Y. Platelet aggregation in patients with primary pulmonary hypertension. Blood Coagul Fibrinolysis 1996; 7: 225-227.

28. Hoeper MM, Sosada M, Fabei H. Plasma coagulation profiles in patients with severe primary pulmonary hypertension. Eur Respir J 1998; 12: 1446-1449.

29. Fuster V, Steele PM, Edwards WD, Gersh BJ, McGoon MD, Frye RL. Primary pulmonary hypertension: natural history and the importance of thrombosis. Circulation 1984; 70: 580-587.

30. Kereveur A, Callebert J, Humbert M, et al. High plasma serotonin levels in primary pulmonary hypertension: effect of long-term epoprostenol (prostacyclin) therapy. Arterioscler Thromb Vasc Biol 2000; 20: 2233-2239.

31. Christman BW, McPherson CD, Newman JH, et al. An imbalance between the excretion of thromboxane and prostacyclin, metabolites in pulmonary hypertension. N Engl J Med 1992; 327: 70-75.

32. Tuder RM, Cool CD, Geraci MW, et al. Prostacyclin synthase expression is decreased in lungs from patients with severe pulmonary hypertension. Am J Respir Crit Care Med 1999; 159: 1925-1932.

33. Brimioulle S, Lejeune P, Vachiery JL, et al. Stimulusresponse curve of hypoxic pulmonary vasoconstriction in intact dogs: effects of ASA. J Appl Physiol 1994; 77: $476-480$ 
34. Langleben D, Barst RJ, Badesh D, et al. Continuous infusion of epoprostenol improves the net balance between pulmonary endothelin 1 clearance and release in primary pulmonary hypertension. Circulation 1999; 99: 3266-3271.

35. Boyer-Neumann C, Brenot C, Wolf M, et al. Continuous infusion of prostacyclin decrease plasma levels of t-PA and PAI-1 in primary pulmonary hypertension. Thromb Haemost 1995; 73: 727-738.

36. Crowley S, Dempsey EC, Horwik KB, Horwik LD. Platelet-induced vascular smooth muscle proliferation is modulated by the growth amplification factors serotonin and adenosine phosphate. Circulation 1994; 90: 1908-1918. 